\title{
IMPACT OF SYRIAN REFUGEES ON LEBANESE CITIES: A CASE STUDY OF SOLID WASTE MANAGEMENT
}

\author{
Dr. Mansoor Ali*
}

\begin{abstract}
Lebanon is one of the higher density countries in the world with a total population of four and a half million over an area of 10,000 square-kilometers. Its cities host around one and a half million displaced persons from Syria (including one million officially registered refugees), which is thirty percent of Lebanese population. The Government of Lebanon does not allow permanent refugee camps and the shelter provision is restricted to Informal Tented Settlements (ITS), but only twenty percent of the refugees are living in ITS ${ }^{1}$. The majority are integrated within the host population cities in rented housing, un-finished buildings and closed communities within communities. This has an impact on many basic services including solid waste management.
\end{abstract}

This paper focuses on the solid waste services in Lebanese cities after Syrian crisis. The displaced Syrian population generates waste, which adds to the municipal stream and adds to already burdened collection system, which is politically complex. Hence, any improvements in solid waste management for refugees has to negotiate through the existing challenges. There is a lack of clarity in the responsibility to provide basic services to refugees and their rights to work, stay, travel etc. While there are international and national organisations supporting refugees, there are many limitations on what can or cannot be done with the refugees' population. For example, an organization can provide the communal bins near ITS, but municipality may or may not agree to transport those for further disposal, as the Syrian refugees do not pay taxes directly to municipalities.

This paper is based on author's field work and case study methodology in this context and focuses on the background and complexity of solid waste service in Lebanese cities. The paper explains various institutional tensions in the given context and what can be done to overcome this. The paper concludes that in a situation like Lebanon, refugees supporting interventions must be prepared with a full understanding of the urban complexities, as there are 'cities beyond cities' to address.

Keywords: Syria, Solid waste management, Refugees, Lebanon

\section{INTRODUCTION}

In the last seven years, more than five million people have left Syria as refugees, while six million are internally displaced. Many face repeated displacements to Syrian neighbouring countries like Turkey, Lebanon and Jordan (Government of Lebanon and UN, 2017). Lebanon, Syria and Jordan have a history of migratory seasonal workers exchanges too. Lebanon has a land area of ten thousand square kilometers (Pakistan has an area of eight hundred thousand square kilometers for comparison) and a rolling terrain with hills and mountains.

All three refugee hosting countries have different policies towards Syrian refugees, especially in terms of shelter, rights to live and work. The Government of Lebanon (GoL) does not allow permanent refugee camps and the shelter provision is restricted to ITS. The integrated refugees' population receives services. For example, they generate waste, which adds to the local municipal stream and adds to already burdened collection system. Common guidelines and practices to support refugees assume a camp like situation and very little is researched and published on supporting refugees, already integrated with host population.

Refugees situation in Lebanon is not about 'camps management'. Any intervention has to negotiate with the institutional challenges and opportunities in the

* Dr. Mansoor Ali, Visiting Professor, Loughborough University, U.K. Email correspondence: mansoorali57@hotmail.com

1 Various sources such as UNHCR database and Amnesty International. 


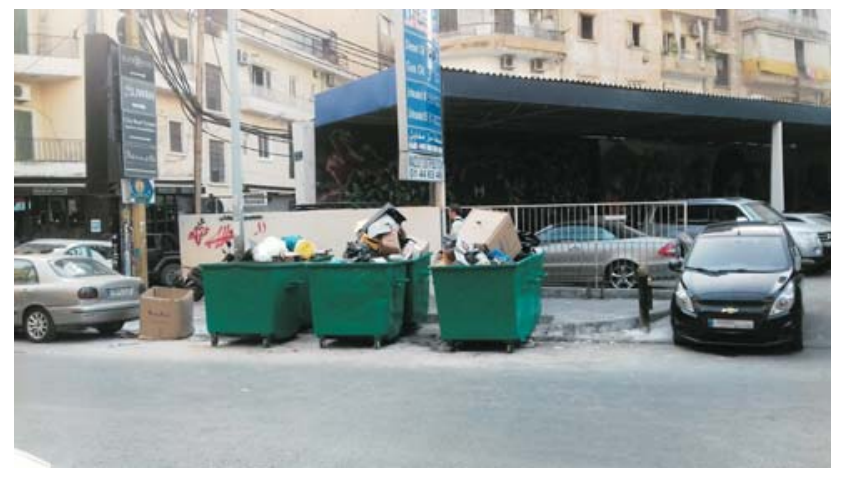

Figure 1: Communal waste collection bins near refugee camps.

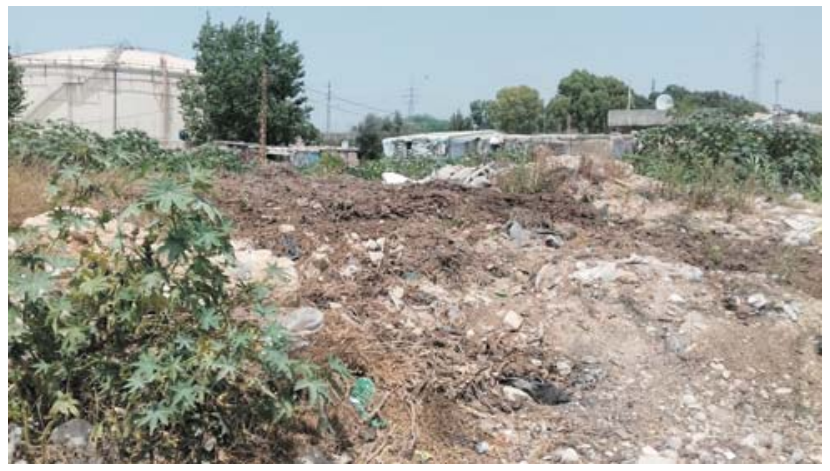

Figure 2: A waste dumping ground in Lebanon near a refugee camp site. country. This includes political support, relevant ministries and municipalities lead by mayors. For example, an organization can provide the communal bins near the camps (figure 1), but the municipality may or may not agree to transport those for final disposal. The paper explains the complexity of solid waste system in the context of a middle income country hosting the refugees. While it also explores the possibilities of low investment and high impact options to improve solid waste systems.

\section{SOLID WASTE MANAGEMENT IN LEBANON}

Solid waste services are generally politically complex and receive quick public reaction if they fail to deliver as per expectations. Lebanon is not an exception in this respect. It is already a politically sensitive public service, facing severe challenges, and spans across a number of policy issues and around various stakeholders. Despite this, Lebanon provides a hundred percent waste collection service to its citizens. This level of service has been maintained even after the refugees' crisis.

Solid waste sector in Lebanon faces a number of challenges. These challenges include developing and maintaining large infrastructure such as landfills and incinerators, an expectation to continue to provide a reliable service to the citizens with increased population and un-certain budgets, un-certainty regarding maintenance of large infrastructure and lack of clarity of roles and responsibilities between federal government and municipalities. Shortage and high prices of suitable land, (figure 2) influx of refugees and additional burden of services on the hosting municipalities have added further complexity. Political and citizens response is divided over Lebanese support to Syrian refugees.

During the discussion on waste services, citizens frequently refer to the '2015 waste crisis' when large landfills which had reached their lifespan had to be closed down with a big impact on the collection system, leading to the accumulation of waste in streets of Beirut and Mount Lebanon regions. This brought citizens, media and civil society organisations protesting against the situation and politicians had to intervene. The vulnerable situation of final disposal of solid waste in Lebanon was also debated in the region, with Cyprus and Turkey worried for the impact and pollution of the Mediterranean Sea and shores, with a potential negative impact on the environment and tourism industry.

Lebanon's own political situation has an impact on the institutional framework required for solid waste management. This is often characterized by a lack of clarity on the division of responsibilities of the different public organisations for waste management. The impact of this lack of clarity has several major implications. This is particularly visible in the procurement of large infrastructure (large landfills, incinerators, waste to energy, large scale composting and recycling plants, etc.) and the lack of acceptance of responsibilities by the municipalities, which citizens expect, but ministries had promised to deliver. Projects which do not receive adequate investment from government, end up being implemented directly but reluctantly by the municipalities.

Institutional responsibilities span across a number of ministries. The Ministry of Environment (MoE) is responsible for reviewing all studies and tender documents related to solid waste, participating in 
committees to decide on construction or changes related to solid waste treatment facilities and landfills, approval of environmental assessments, as well as authorizing facilities and providing permits, preparing and formulating master plans for the management of solid waste and defining environmental limit values for the disposal of non-hazardous solid waste (and liquid waste) in water bodies and on soil, as well as supervision and inspection of compliance. Currently MoE is preparing an inventory of an estimated seven hundred dumpsites in the country, which will inform the SWM draft strategy under preparation. While MoE is responsible for a number of areas in waste management, it does not manage the municipalities. The Ministry of Interior and Municipalities (MoIM) sets out the responsibilities of municipalities and manages the allocation and distribution of funds from the Independent Municipal Fund under the control of the Ministry of Finance. The Ministry of Public Health aims to improve population health by ensuring equal access to reliable health services. It also approves health facilities and thus is indirectly responsible for ensuring the existence of healthcare waste management facilities. Ministry of Public Health has only got an in-direct involvement in Solid Waste Management.

The Council for Development and Reconstruction (CDR) was formed in the year 1992 and was assigned the responsibility to construct large infrastructure for the management of solid waste facilities in Beirut and Mount Lebanon areas. CDR contracts out the private sector for the services of the collection, transport, treatment and disposal of the municipal waste for Beirut and Mount Lebanon, the largest urban areas in the country. It is also responsible for the rehabilitation of landfills in these areas. The CDR works closely with the concerned ministries in an effort to support infrastructure development, lends support to the CoM and manages infrastructure projects financed through international loan agreements. The CDR prepares plans and strategies together with the MoE and MoIM.

Municipalities are the leading organisations in providing solid waste services and planning for the future. These are responsible for solid waste collection and encourage sorting at source, which strongly depends on the cooperation from citizens. Municipalities highlight the urgent need for infrastructure for the final disposal, including landfills and incinerators. There are eleven hundred and eight municipalities in Lebanon, mostly operating according to a law from 1922, which established that municipalities are governed by elected municipal councils (Muhafaza), which are agents of the central government and where prior approval has to come from the central government for most decisions. Many of the municipalities have come together in municipal unions (reaching fifty one unions in 2013), grouping more than two-thirds of the one thousand one hundred and eight municipalities. The unions of municipalities have legal status with administrative and financial autonomy. The purpose of a union is to promote inter-municipal cooperation for projects of public interest or to implement large-scale technical projects that benefit all municipalities. SWM requires regional cooperation, hence the concept of the union is important. Municipalities are at the frontline of refugee crisis and there are municipalities where refugees' concentration is high.

\section{TOWARDS INTEGRATED SOLID WASTE MANAGEMENT}

In 2005 and 2006 the preparation of a Draft Law and Plan on Integrated Solid Waste Management (ISWM) was initiated by the CDR. This introduced many important aspects into the policies. For example, this was the first instance when recycling was included in the policy at a higher level. ISWM focused on reducing the quantities of waste streams requiring disposal, promoted waste reduction, encouraged source separation, recycling and energy recovery. The Draft Law also assigned responsibilities to a ministerial committee headed by the MoE to prepare strategies, adopt the "Polluter Pays Principle" and assign responsibilities to the local authorities to manage waste. The Draft Law and Plan was approved by the Council of Ministers in June 2006, however it has not been implemented, partly due to the 2006 war and partly due to disagreements (UNESCWA, 2016). However, the existence of this law is an important leverage to promote actions concerned with waste recycling, reuse and reduction at scale, which are important requisites for a modern solid waste system, with or without refugees.

In 2009 a Ministerial Declaration committed the Government of Lebanon to protect the environment by finding alternatives to open dumping and solutions for SWM, implementing energy conservation measures such as adopting waste-to-energy technologies for urban areas and major cities, promoting ISWM, covering municipal, industrial and hazardous waste 
and defining guidelines for treatment of special waste, such as e-waste. The declaration also called for engaging the private sector in SWM services and mandated the Ministry of Environment and Water to draft regulation for Waste to Energy (WtE) generation by the private sector. The decision led to the development of the National Integrated Strategy for SWM, presented by $\mathrm{MoE}$ to the Council of Ministers (CoM) in 2010 with a policy framework for twenty five years. The strategy included rehabilitating dumps, replacing technologies previously foreseen for sorting, composting and landfilling by $\mathrm{WtE}$ technology (with moisture reduction and electricity generation), and building transfer stations to decrease the cost of transporting waste. However, at the time of the fieldwork, the CoM had not yet approved the strategy.

A number of UN agencies and civil society organisations are also implementing solid waste management activities. The most prominent and perhaps the most impressive is the work of Arc-en-ciel (AEC), a national civil society organization (AEC, 2015). This was established in 1985, working on the model of social enterprises and supporting people in needs and people with disabilities. AEC works across Lebanon and has seven other programmes. SWM activities fall under the Sustainable Agriculture and Environment programme. AECrc-en-ciel has more than a decade of experience in SWM, including setting up of a network for collection of recyclables and management of eighty percent of hospital waste in the country. The organization considers itself a leading player in determining Lebanon's waste strategy, assuming that learning from projects can be useful for SWM policy. Currently AECArc-en-Ciel advises municipalities and builds capacity in programme development, technical skills development and implementation. They are also involved in collection of recyclable material and operation of three sorting centers, as well as piloting a composting programme. AECrc-en-ciel sees an emerging interest in recycling, with an estimated five hundred organisations already working in it at different scales. ARC brings in institutional memory and technical expertise for future work in solid waste management.

\section{TECHNICAL CONSIDERATIONS}

Lebanon has a range of reports and data available on solid waste management. According to UN Habitat the waste generation rate per capita per day, is estimated at $0.97 \mathrm{~kg} /$ day in urban areas, 0.79 in rural areas and
0.50 for refugees. According to these statistics, Lebanon generates seven thousand one hundred and forty five tons of garbage per day or two and a half million tons a year. The largest generation of waste comes from Beirut and Mount Lebanon regions, estimated at two thousand eight hundred and fifty tons per day. In addition to this, an estimated twenty five tons of medical waste is generated each year, with five tons of the total being infectious waste (AEC, 2015). An estimated fifty two and half percent of waste is organic in nature, with sixteen percent paper and cardboard and eleven and half percent plastics. Thirty six percent of municipal solid waste is composed of recyclable material. However, so far in Lebanon only eight percent of all waste generated is recycled, due to the nature of the system, lack of awareness, political commitment, and lack of municipal initiative and resources.

According to Sweep-Net (2014) municipal solid waste collection (excluding Syrian refugee ITS) was up to one hundred percent in urban areas and ninety nine percent in rural areas. The collection system in general is through the provision of large public bins with capacity of twelve hundred litres where residents bring their waste, which is often mixed, and there is little practice of reducing waste, sorting at source and recycling. The high level of recyclables and organic content in Lebanon's municipal waste highlights the important opportunity of re-using, recycling and recovery. Where recycling is practiced, there are two types of systems in place;

1) Where waste is collected in compactor trucks and separated at transfer points. This is more common in larger municipalities, where streams are high in volume (figure 3 ).

2) Where it is separated at source and brought to be cleaned to sorting stations. This is practiced more in smaller municipalities, where pilot programmes are being tested (figure 4).

In the second system, the quality of separated material is good, while there is an additional cost of separated garbage collection. The first system requires effort to separate waste from mixed waste, while this service may be providing a cost-effective collection service.

Due to shortage of land and high quantities of waste, final disposal of solid waste is a critical issue in Lebanon. Currently around seventy seven percent of 


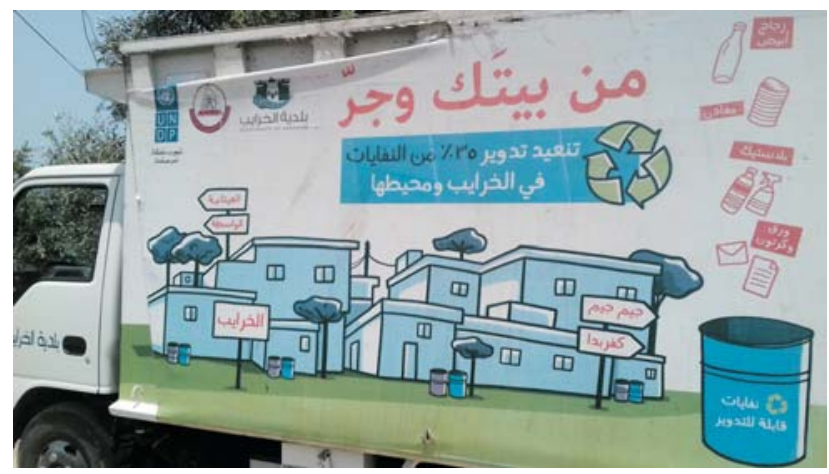

Figure 3: A compactor truck which collects waste.

the waste is either disposed in sanitary landfill or at open dump sites, and twenty three percent is recovered for recycling and composting. The waste crisis of 2015 is an important evidence of the critical nature of waste disposal, when the closure of Nahme Landfill caused a general collapse of waste collection system in Beirut and Mount Lebanon. Some reports suggest that there was a sharp increase in the open dumping of waste after 2015 crisis. There is a desire to invest in large infrastructure solutions, such as waste to energy plants by municipalities, while waste reduction, recycling and composting is favoured by many stakeholders. Civil society sees recycling as an opportunity to create jobs and protect the environment. This may result in lesser quantities of waste requiring final disposal. Figures show that recycling and composting in Lebanon are still quite limited in relation to the potential. Eighty percent of the waste has potential for recycling or composting, and only twenty three percent is effectively processed and valorized (Arc-En-Ciel and AEC, 2015).

The cost of waste collection and final disposal varies in Lebanon. These costs are not available to the public and based on estimates made by previous studies, these costs also do not take into account the environmental externalities. One of UN's studies estimated that in 2015 the total cost of SWM was three hundred twenty million US dollars. On average, SWM consumes thirty three percent of the municipal budget, which is within the international estimates of twenty to forty percent of the municipal budget. One municipality estimates the following cost:

- Collection and transport: Eighteen to thirty two US dollars per ton (urban areas consuming higher costs, Beirut and Mount Lebanon are among

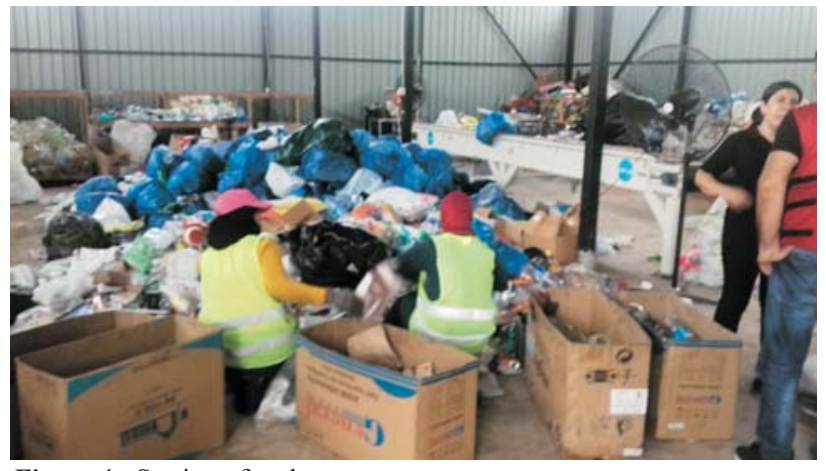

Figure 4: Sorting of garbage at source.

highest due to urbanization and contractual arrangements);

- Landfilling: Thirty to fifty US dollars per ton (Beirut and Mount Lebanon among the highest).

\section{CONCLUSIONS AND RECOMMENDATIONS}

The fieldwork in Lebanon reveals a number of important aspects:

1) The refugees' crisis in Lebanon needs a different approach than 'camps management' or 'life saving' approaches, common in humanitarian work. Since refugees are integrated within the host population, the practitioners need a thorough understanding of the urban complexities, as refugees' form cities within and beyond the current cities. Lebanon provides an important context for refugees' integration and what can be done to support them needs to be looked into. The urban complexity needs to be comprehended and the concept of cities within cities needs a further understanding with respect to solid waste management issues and opportunities.

2) Refugees are often seen as additional burden on municipal services, such as solid waste management. However, there is a lack of clarity on the burden due to past issues, politics and institutional complexities and added needs from the refugees. Needs assessments and baseline are to be designed to provide clarity on the added burden. Otherwise, refugees support programmes may start addressing the past challenges of the cities. This may not provide targeted support to 
the refugees. In the case of Lebanon, solid waste service are politically complex and addition of refugee population is just one dimension of the problem. The dimensions of solid waste management problems that can further an understanding of potential issues that need to be identified.

3) Direct support to refugees is only allowed by the host governments, while large infrastructure investment in the name of addressing the refugees crisis may not sustain. This leaves some large questions regarding the nature of programmes, where global funds are already allocated. In the case of Lebanon, one needs to have a mix of programming and cause and effect studies could provide much needed information regarding the impactful programmes. These studies can also be of great value to other regions of the world, where refugees are hosted or populations are internally displaced. Without this evidence the project support may continue to be provided with the two extremes of large infrastructure provision and low investment and low risk type interventions. The needs may be a combination of the two types. One potential opportunity could be that the donors invest in host community infrastructure in order to provide support to the local population and the refugees.

\section{REFERENCES}

AEC, Arc-En-Ciel (AEC), 2015, “Municipal Waste Management Plan”, AEC.

Government of Lebanon and UN, 2017, “Lebanon Crises Response Plan 2017-2020", United Nations.

Sweep-Net, 2014, "Country Report on the Solid Waste Management in Lebanon", Sweep-Net and GIZ.

UN ESCWA, 2016, "Integrated Solid Waste Management in the Arab Region, Regional Report. Case Study on Lebanon. United Nations Economic and Social Commission for West Asia”, UN-published draft. 